Volume 10 No. 2 September 2019

P-ISSN 2086-6178 E-ISSN 2579-3292

http://ejournal.bsi.ac.id/ejurnal/index.php/jkom

\title{
Implementasi Program Bina Lingkungan Corporat Social Responsibility PT Pertamina Dalam Upaya Pelestarian Ekosistem Laut
}

\author{
Siti Qona'ah \\ Universitas Bina Sarana Informatika Jakarta \\ e-mail: siti.sqa@bsi.ac.id
}

Cara Sitasi: Qona'ah Siti. Implementasi Program Bina Lingkungan Corporat Social Responsibility PT Pertamina Dalam Upaya Pelestarian Ekosistem Laut. Jurnal Komunikasi 10(2), 153-160.

\begin{abstract}
Indonesia is a maritime country, The economic system of the people on the coast depends on the natural resources of the sea which produce various marine and fishery products. With a damaged marine environment due to illegal fishing, natural disasters, and damaged marine ecosystems activities that have the potential to protect the marine environment are needed. To preserve Indonesia's marine ecosystem, Pertamina is implementing an environmental development program which is one of its corporate social responsibility programs. Pertamina is committed to always prioritizing the balance and preservation of nature, the environment, society. Implementation of environmental development programs carried out includes providing support for Wasi, providing aid for environmental education props and Coral Reef Rehabilitation. This research is to find out the implementation of Pertamina's corporate social responsibility environmental development program in the preservation of marine ecosystems. In this study, researchers used a qualitative approach and case studies, as a research method that illustrates that the implementation of the corporate social environmental development program will benefit the community in the preservation of Indonesia's marine ecosystem. By improving human, natural and environmental welfare, Pertamina will be able to achieve sustainable business growth.
\end{abstract}

Keywords: Corporate Social Responsibility, Preservation of Marine Ecosystems

\section{PENDAHULUAN}

Indonesia merupakan Negara maritim dimana sistem perekonomian masyarakat pesisir pantai sebagian besar sangat bergantung pada sumber daya alam di laut yang menghasilkan berbagai produk kelautan dan perikanan Hal ini bisa terlihat dari banyaknya profesi yang mengandalkan sumber daya laut sebagai objek utama sebagai mata pencaharian. Dengan kondisi seperti ini Indonesia harus mengatasi berbagai ancaman keamanan maritim seperti illegal fishing, bencana alam, kerusakan ekosistem laut. pembajakan, perompakan, klaim batas negara penyelundupan barang, narkoba dan manusia.

Ancaman illegal fishing misalnya, data yang diperoleh dari Dirjen Perikanan Tangkapan Kementerian Kelautan dan Perikanan (KKP) Zulficar Mochtar, setiap tahunnya laut Indonesia selalu diganggu oleh para pencuri ikan. Aksi yang dilakukan secara ilegal, tidak dilaporkan, dan tidak diatur (illegal, unreported, unregulated fisheries/IUUF) itu, membuat Indonesia harus menelan kerugian setiap tahunnya hingga mencapai
USD20 miliar. "Itu adalah aktivitas yang menjadi ancaman serius bagi sumber daya perikanan nasional, karena itu di dalamnya terdapat aktivitas penangkapan ikan lintas negara," Aktivitas IUUF bisa mengkibatkan degradasi dan hilangnya ekosistem pesisir dan laut yang ada di seluruh kawasan, yaitu hutan bakau, rumput laut, dan terumbu karang yang masuk dalam kelompok ekosistem laut besar Indonesia (Indonesian Seas Large Marine Ecosystem/ISLME). (M, 2019b)

Sekretaris Jenderal Koalisi Rakyat Untuk Keadilan Susan Herawati menjelaskan, "ancaman kerusakan ekosistem di laut, juga disebabkan oleh pencemaran industri, penangkapan ikan berlebih, reklamasi pantai, dan pengasaman laut sebagai dampak perubahan iklim".(M, 2019a)

Kerusakan ekosistem laut lainya yaitu dari pencemaran plastik dengan ditemukannya Seekor paus sperma yang ditemukan mati terdampar di perairan Pulau Kapota, Taman Nasional Wakatobi, Sulawesi Tenggara, Senin , 19 november 2018, menelan hampir enam kilogram plastik dan sandal jepit.(BBC.Com, 2019) 
Ketua Pusat Kajian Sumberdaya Pesisir dan Lautan (PKSPL) IPB Dr Ario Damar mengatakan Pencemaran laut yang mengancam biota laut tidak hanya berasal dari sampah plastik. Akan tetapi juga sampah organik (kayu, sisa makanan, sisa tubuh makhluk hidup) dan gumpalan material berminyak. "Masalah di laut tidak hanya soal pencemaran plastik, namun juga pencemaran laut lainnya," . lebih lanjut Ario menjelaskan "jenis pencemaran perairan yang dominan di Indonesia terdiri dari pencemaran organik mudah urai (nutrien), organik sulit urai dan persisten, logam berat, minyak, pestisida, suhu dan kekeruhan".(Alamsyah, 2019)

Ancaman kerusakan ekosistem lainnya yaitu keberlangsungan ekosistem terumbu karang. Menteri Kelautan dan Perikanan Susi Pudjiastuti mengatakan "Keberlangsungan ekosistem terumbu karang, menjadi terancam karena eksploitasi ikan karang hidup (live reef food fish/LRFF) yang hingga saat ini masih menjadi salah satu komoditas yang sangat diminati di pasar internasional, dengan meningkatnya eksploitasi ikan karang hidup bisa terjadi, karena saat ini komoditas tersebut menjadi salah satu bintang utama ekspor dari berbagai negara ke negara tujuan utama seperti Hong Kong dan Tiongkok. Dalam setahun, ikan karang yang diperdagangkan ke dua negara tersebut berkisar 20 ribu-30 ribu metrik ton (MT) dengan nilai lebih dari USD1miliar.(M, 2019b)

Dari berbagai permasalahan tersebut, di perlukan perhatian berbagai pihak untuk menangani permasalahan pencemaran lingkungan khususnya pelestarian ekosistem laut. ekosistem pesisir dan laut merupakan habitat yang penting bagi keanekaragaman hayati dan produktivitas perikanan di Indonesia

Corporate Social Responsibility merupakan salah satu kewajiban yang harus dilaksanakan oleh perusahaan sesuai dengan isi pasal 74 Undangundang Perseroan terbatas (UUPT) yang terbaru yakni UU no 40 tahun 2007. Melalui undangundang ini, Industri atau koperasi wajib untuk melaksanakannya, tetapi kewajiban ini bukan suatu beban yang memberatkan. Pembangunan suatu negara bukan hanya tanggung jawab pemerintah atau industri, tetapi setiap insan manusia berperan untuk mewujudkan kesejahteraan sosial kualitas hidup masyarakat

Untuk mengatasi permasalahan lingkungan ekosistem laut Pertamina melaksanakan program Bina Lingkungan yang merupakan salah wujud tanggung jawab sosial lingkungan. Program Bina Lingkungan yang dilaksanakan merupakan program pemberdayaan kondisi sosial masyarakat di sekitar wilayah operasi perusahaan. Hal ini sejalan dengan komitmen pertamina yaitu Sebagai perusahaan energi nasional, Pertamina berkomitmen untuk senantiasa memprioritaskan keseimbangan dan kelestarian alam, lingkungan dan masyarakat. Dengan menyejahterakan manusia, alam, dan lingkungan, maka Pertamina akan mampu mencapai pertumbuhan bisnis yang berkelanjutan (pertamina, 2019)

Dalam Bina Lingkungan terdapat 7 Sektor Klasifikasi Bantuan sebagai berikut:

1. Bantuan kebakaran dan bencana alam,

2. Bantuan pendidikan dan pelatihan,

3. Bantuan peningkatan kesehatan,

4. Bantuan pelestarian alam,

5. Bantuan sarana ibadah,

6. Bantuan sarfas umum,

7. Bantuan soskem peningkatan kemiskinan (pertamina, 2019)

Bentuk kegiatan corporate social responsibility Pertamina yang telah dilaksanakan dalam program bina lingkungan untuk pelestarian laut antara lain memberikan dukungan terhadap Wasi, memberikan bantuan alat peraga pendidikan lingkungan hidup. Rehabilitasi Terumbu Karang.

Dari uraian tersebut penulis membuat rumusan masalah bagaimana implementasi program bina lingkungan corporat social responsibilty Pertamina dalam upaya pelestarian ekosistem laut?.

Dalam penelitian ini teori yang digunakan antara lain:

\section{Implementasi}

Implementasi adalah suatu "penerapan atau tindakan yang dilakukan berdasarkan rencana yang telah disusun atau dibuat dengan cermat dan terperinci sebelumnya".(maxmanroe.com, 2019)

Tujuan utama implementasi adalah

1. untuk melaksanakan rencana yang telah disusun dengan cermat, baik oleh individu maupun kelompok.

2. Untuk menguji serta mendokumentasikan suatu prosedur dalam penerapan rencana atau kebijakan.

3. Untuk mewujudkan tujuan-tujuan yang hendak dicapai di dalam perencanaan atau kebijakan yang telah dirancang.

4. Untuk mengetahui kemampuan masyarakat dalam menerapkan suatu kebijakan atau rencana sesuai dengan yang diharapkan.

5. Untuk mengetahui tingkat keberhasilan suatu kebijakan atau rencana yang telah 
dirancang demi perbaikan atau peningkatan mutu.(maxmanroe.com, 2019)

\section{Corporate Sosial Responsibility}

Corporate Sosial Responsibility adalah "upaya sungguh-sungguh dari entitas bisnis untuk meminimalkan dampak negative dan memaksimalkan dampak positif operasinya terhadap seluruh pemangku kepentingan dalam ranah ekonomi, social dan lingkungan agar mencapai tujuan pembangunan berkelanjutan." (Emir, 2011)

Corporate Sosial Responsibility didefinisikan sebagai "integrari operasional bisnis perusahaan dan nilai nilai dari semua kepetingan stakeholder, yang terdiri dari konsumen, penyalur barang dan jasa, investor serta lingkungan termasuk juga masyarakat local disekitar perusahaan." (Emir, 2011)

\section{Manfaat Corporate Social Responsibility:}

Agar Corporate Social Responsibility (CSR) dapat dilaksanakan secara terus menerus, Perusahaan harus sudah menggunakan Prinsip Triple Botton Line yang berpijak pada pemikiran bahwa selain mengejar keuntungan, perusahaan juga harus melihat sisi kesejahteraan lingkungan atau dikenal dengan istilah $3 \mathrm{P}$ (profit, People, Planet)

(Wibisono, 2007) menyatakan bahwa "perusahaan yang ingin berkelanjutan harus memperhatikan 3 P". yaitu :

1. Profit (keuntungan) setiap perusahaan pasti akan berlomba-lomba untuk meningkatkan produktivitas dan melakukan efisiensi biaya.

2. People (masyarakat) masyarakat merupakan stakeholder penting bagi perusahaan dikarenakan dukungan masyarakat sangat di perlukan bagi keberadaan, kelangsungan hidup, dan perkembangan perusahaan. Untuk mempekokoh komitmen dalam tanggung jawab sosial, perusahaan perlu memiliki pandangan bahwa CSR adalah investasi kedepan. Karena melalui hubungan yang harmonis dan citra yang baik timbal baliknya masyarakat juga akan ikut menjaga eksistensi .

3. Planet (lingkungan) Lingkungan adalah sesuatu yang terkait dengan seluruh bidang kehidupan kita. Hubungan kita dengan lingkungan adalah hubungan sebab akibat, dimana jika merawat lingkungan, maka lingkunganpun akan memberikan manfaat kepada kita. Keberlanjutan perusahaan hanya akan terjamin apabila perusahaan memperhatikan dimensi sosial dan lingkungan hidup.

\section{Pelestarian}

Pelestarian adalah "melindungi sebanyak-banyaknya keanekaragaman jenis yang hidup di suatu kawasan" (Sastrapradja Setijati D, 2010)

\section{Ekosistem}

Ekosistem adalah "sekumpulan makhluk hidup yang saling membaur dan membentuk suatu sistem ekologi utuh bersama- sama. Bumi sendiri memiliki dua ekosistem besar. Yaitu ekosistem darat dan ekosistem air ." (Ilmugeografi.com, 2015b)

Ekosistem air laut merupakan salah satu jenis ekosistem di Bumi yang dikenal juga dengan ekosistem bahari, Ekosistem air laut ini merupakan ekosistem yang berada di perairan laut. Ekosistem air laut ini terdiri atas beberapa ekosistem lainnya yakni ekosistem perairan dalam, ekosistem pantai pasir dangkal atau bitarol, dan ekosistem pasang surut. Ekosistem air laut ini didominasi oleh perairan asin yang sangat luas dan merupakan ekosistem yang menjadi tempat tinggal berbagai biota laut, mulai dari hewan ber sel satu, mamalia, invertebrata, hingga tanaman- tanaman laut seperti alga dan terumbu karang.(Ilmugeografi.com, 2015a)

\section{METODOLOGI PENELITIAN}

Metodologi pada penelitian ini menggunakan metodologi kualititatif dengan metode studi kasus. "metode studi kasus yaitu metode riset yang menggunakan berbagai sumber data yang bisa digunakan untuk meneliti menguraikan dan menjelaskan secara komprehensif berbagai aspek individu kelompok, suatu program, organisasi atau peristiwa secara sistematis". (Kriyantono, 2006)

(Pawito, 2008) mengemukakan bahwa "dalam penelitian kualitatif, kesimpulan yang dihasilkan pada umumnya tidak dimaksudkan sebagai generalisasi, tetapi sebagai gambaran interpretative tentang realitas atau gejala yang diteliti secara holistic dalam setting tertentu, disini dikandung arti bahwa temuan apapun yang di hasilkan pada dasarnya bersifat terbatas pada kasus yang di amati. Oleh karena itu, prinsip berfikir induktif lebih menonjol dalam penarikan kesimpulan dalam penelitian komunikasi kualitatif'.

Metode kualitatif menurut Bogdan \& Taylor "diharapkan mampu menghasilkan suatu uraian mendalam tentang ucapan, tulisan dan tingkah laku yang dapat diamati dari suatu individu, kelompok masyarakat, organisasi tertentu dalam suatu konteks setting tertentu yang di kaji dari sudut pandang yang utuh komprehensif dan holistic"(Ruslan, 2011)

(Moleong, Lexy, 2002) mengemukakan bahwa "salah satu karakterisik dalam penelitian kualitatif adalah deskriptif. Dalam hal ini data yang dikumpulkan berupa kata-kata, gambar dan bukan angka-angka. Hal ini disebabkan adanya penerapan metode kualitatif. Selain itu, semua yang di kumpulkan berkemungkinan menjadi kunci terhadap apa yang sudah di teliti. Dengan demikian laporan 
penelitian akan berisi kutipan-kutipan data untuk memberi gambaran penyajian laporan tersebut".

Teknik pengumpulan data dalam penelitian ini menggunakan observasi, wawancara, studi pustaka, dokumentasi. Observasi menurut (Djaelani, 2013) berasal dari kata observation yang berarti pengamatan. Metode observasi dilakukan dengan cara mengamati perilaku, kejadian atau kegiatan orang atau sekelompok orang yang diteliti. kemudian mencatat hasil pengamatan tersebut untuk mengetahui apa yang sebenarnya terjadi. Lebih lanjut dijelaskan observasi atau pengamatan dapat dilaksanakan dengan bantuan alat pengamatan yang berupa, daftar cek, tabel sosiometri, catatan lapangan, jurnal harian, alat perekam elektronik dan format lainnya.

Dalam penelitian penulisan menggunakan observasi dengan mengamati mengenai program Bina lingkungan corporate social responsibility pertamina dalam upaya pelesatrian ekosistem laut dengan mendapatkan bantuan dari alat pengamatan berupa pemberitaan di media online. Wawancara merupakan "suatu bentuk komunikasi untuk mencapai tujuan tertentu. Dalam wawancara pihakpihak yang diwawancarai dan yang mewawancarai terlibat dalam proses kontak dan pertukaran informasi” (Hardjana, 2018). Pihak yang mewawancarai adalah orang yang ingin mendapatkan informasi. wawancara yang diperoleh berupa hasil pernyataan yang disampaikan oleh Ignatiud Tallulembang Studi Pustaka yaitu "teknik pengumpulan data yang dilakukan dengan mempelajari peraturan-peraturan, buku-buku referensi, laporan-laporan, majalah-majalah, jurnaljurnal dan media lainnya yang berkaitan dengan obyek penelitian (Gunawan, 2016) Dalam hal ini penulis menggunakan buku, jurnal atau sumber tertulis.

Dokumentasi (Ningrum, 2015) dalam Hamidi Metode dokumentasi adalah "informasi yang berasal dari catatan penting baik dari lembaga atau organisasi maupun dari perorangan". Dokumentasi pada penelitian ini berupa foto, news release Pertamina mengenai kegiatan yang dilaksanakan oleh pertamina yaitiu program bina lingkungan dalam upaya pelestarian ekosistem laut Indonesia.

\section{HASIL DAN PEMBAHASAN}

Implementasi program Bina lingkungan Corporat Sosial responsibility pertamina dilaksankan dalam bentuk kegiatan pelestarian lingkungan. Pelestarian lingkungan mencakup lingkungan laut Indonesia, hal ini dikarenakan Indonesia merupakan negara kelautan terbesar di dunia dengan ekosistem laut besar di wilayah Negara Indonesia terdapat 500 spesies terumbu karang, 2.500 spesies ikan laut, 47 spesies tanaman bakau, dan 13 spesies tanaman lamun. Untuk itu diperlukan perhatian khusus dalam menjaga sumber daya dan kekayaam laut sebaikbaiknya.

Pertamina sebagai perusahaan BUMN melalui program Bina Lingkungan yang merupakan salah satu dari program Corporate Sosial responsibility berupaya untuk memberikan manfaat kepada masyarakat melalui pelestarian ekosistem laut di Indonesia.

Anggaran dalam mewujudkan program corporate aosial responsibility Pertamina melalui pemanfaatan dana dari bagian laba BUMN dan bersifat hibah. Besaran dana Bina Lingkungan adalah 2\% dari Prognosa laba peusahaan. Program bersifat bantuan langsung berupa hibah baik dalam bentuk dana maupun fisik sesuai dengan permintaan masyarakat. Program menjangkau seluruh Kota dan Kabupaten di Indonesia. Program Bina Lingkungan membantu masyarakat untuk dapat mencapai kesejahteraan dan kondisi sarana fasilitas umum yang lebih layak.(pertamina, 2019)

Berikut ini Implementasi Program Bina Lingkungan corporate social responsibility yang dilaksanakan Pertamina:

\section{Pertamina dukung Wanita Selam Indonesia dalam pecahkan rekor dunia selam}

Implementasi program Bina lingkungan corporate social responsibility yang dilaksanakan yaitu dukungan Pertamina dalam mewujudkan upaya Wanita Selam Indonesia (Wasi) untuk mengkampanyekan edukasi mengenai pentingnya biota bawah laut Indonesia. Tujuan Dukungan terhadap kegiatan ini untuk memberikan manfaat luas kepada masyarakat sekitar.

Direktur Megaproyek Pengolahan dan Petrokimia Pertamina Ignatiud Tallulembang menyatakan "Maka, sejalan dengan itu, Pertamina dengan bangga mendukung kegiatan tersebut sebagai salah satu wujud jiwa sosial korporasi terhadap upaya pengembangan dan kepedulian sumberdaya Indonesia," (Nasrulhak, 2019)

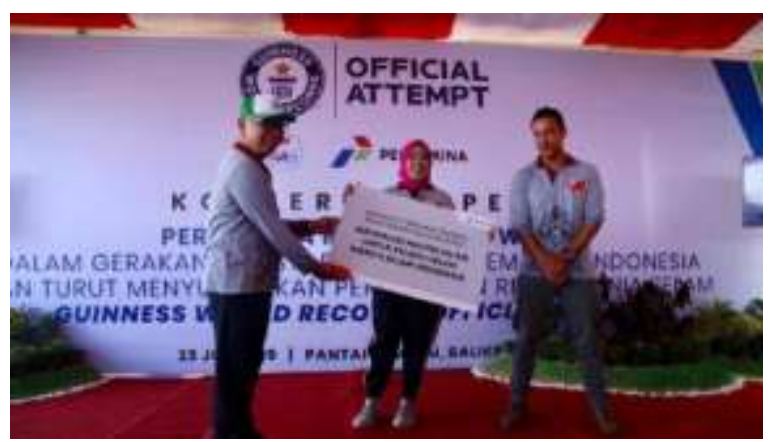




\section{Sumber : doc pertamina}

\section{Gambar 1}

Penyerahan Sertifikasi Master selam untuk Pelatih Selam wanita Indonesia

Program Bina lingkungan dalam bentuk pelestarian laut ini merupakan kerja sama Pertamina dengan Wasi.

Wasi, yang merupakan organisasi di bawah naungan Persatuan Olahraga Selam Seluruh Indonesia (POSSI), memiliki agenda besar pada 3 Agustus 2019 di Manado, Sulawesi Utara. Agenda tersebut adalah pemecahan 3 rekor dunia, yaitu penyelaman massal bertarget 3.000 penyelam, rantai manusia terpanjang dalam air, dan pembentangan bendera terlebar di dunia, Kegiatan diselenggarakan untuk memperingati Hut ke 74 Republik Indonesia serta untuk mempromosikan laut di Indonesia, seperti kelestarian alam, lingkungan hidup dan olah raga selam.

Ketua Umum Wanita Selam Indonesia Tri Tito Karnavian mengatakan "Wasi berupaya untuk terus meningkatkan kesadaran pentingnya laut bagi kehidupan. Melalui kerja sama dengan berbagai pihak salah satunya Pertamina, Wasi akan terus berperan aktif dalam mendukung dan mengembangkan program-program pelestarian laut dengan memanfaatkan pengetahuan dan keahlian kami sebagai penyelam”. (Nasrulhak, 2019)

Selain kegiatan pemecahan rekor dunia, Wasi melakukan aksi bersih laut dan pantai Menado dengan tujuan mensosialisaikan pembersiham laut Indonesia dalam mengkampayekan Dive Again Debris, yaitu gerakan yang mengajak penyelam untuk mencintai laut melalui kegiatan membersihkan laut dari puing dan sampah di lingkungan ekosistem laut Indonesia.

\section{Pertamina Lengkapi sekolah Mangrove Dengan Alat Peraga}

Implementasi Program Bina Lingkungan Corporate Social Responsibility Pertamina dalam upaya pelestarian laut laut lainnya adalah Pertamina menyerahkan bantuan alat peraga pendidikan lingkungan hidup (PLH) tematik Mangrove kepada 26 Sekolah Dasar (SD) di Kabupaten Indramayu. Bantuan alat peraga diserahkan secara simbolis oleh Unit Manager Communication, Relation \& CSR RU VI Eko Kristiawan kepada Kepala Sekolah SDN Pabean Udik 1 Tasrikhah.

Penyerahan alat peraga ini merupakan salah satu rangkaian program bina lingkungan Corporate Sosial responsibility Pertamina RU VI Balongan Sekolah Mangrove untuk melengkapi dan memaksimalkan media pembelajaran sekolah mangrove yang sebelumnya Pertamina telah membagikan 5.502 buku Pendidikan Lingkungan Hidup (PLH) tematik Mangrove.

Bentuk alat peraga berupa magnet keanekaagaman hayati, magnet jaring-jaring makanan, poster fauna hutan mangrove, poster pencegah banjir dan poster pencegah tsunami, Diharapkan dengan alat peraga tersebut informasi yang disampaikan bisa lebih mudah diterima sehingga meningkatkan minat dan semangat siswa saat belajar.

Manager Communication, Relation \& CSR RU VI Eko Kristiawan menyatakan "Alat peraga bisa menjadi sarana dalam pembelajaran guna memotivasi anak agar dapat berpikir efektif dan efisien. Sehingga nantinya tumbuh rasa partisipasi dalam perlindungan, pengelolaan, dan pengembangan kawasan hutan mangrove".(Donald, 2019)

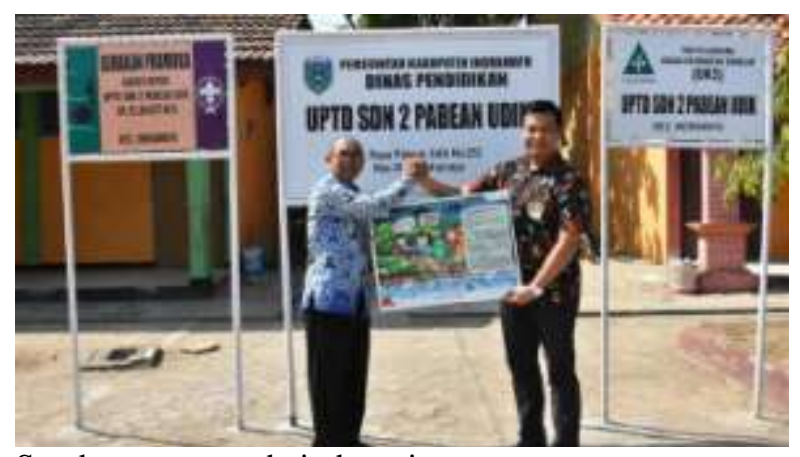

Sumber : www.cnbcindonesia.com

Gambar 2

Penyerahan secara simbolis pemberian bantuan alat peraga pendidikan lingkungan hidup oleh manager communication, relation \& CSR RU VI Eko Kristian kepada kepala sekolah SDN Pabean Udik 1 Tasrikhah

Kepala Sekolah SDN Pabean Udik 1 Tasrikhah saat menerima bantuan dari RU VI menyampaikan terima kasih atas bantuan media pembelajaran yang diberikan melalui program Sekolah Mangrove CSR Pertamina RU VI, Tasrikhah menyatakan "dengan alat peraga pembelajaran yang diberikan sangat bermanfaat untuk meningkat minat siswa belajar untuk meninbulkan rasa ingin tahu yang lebih jauh sehingga memberikan pembelajaran yang maksimal di kelas". (Donald, 2019)

SDN Pabean Udik 1 merupakan salah satu sekolah mangrove yang di didikan oleh RU VI Balongan menjadi pendidikan muatan lokal untuk siswa kelas 4, 5, dan 6 yang di 6 kecamatan yang berada di wilayah pesisir Kabupaten Indramayu, yaitu Kecamatan Balongan, Indramayu, Cantigi, Pasekan, Karangampel, dan Juntinyuat yang dalam pelaksanaannya bekerja sama dengan Dinas Pendidikan Kabupaten Indramayu.(Donald, 2019) 


\section{Rehabilitasi Terumbu Karang}

Implementasi Program Bina Lingkungan Corporate Social Responsibility Pertamina dalam upaya pelestarian laut lainnya adalah rehabilitasi terumbu Karang Taman Wisata Alam Laut (TWAL) Pulau Pombo, Maluku. Program yang dijalankan oleh Pertamina MOR VIII - TBBM Wayame bekerja sama dengan Balai Konservasi Sumber Daya Alam (BKSDA) Maluku ini memfokuskan pada upaya konservasi dengan teknik transplantasi di beberapa titik terumbu karang yang mengalami kerusakan karena penggunaan bom oleh aktivitas manusia.

Taman Wisata Alam Laut (TWAL) Pulau Pombo terletak di antara Pulau Ambon dan Pulau Haruku dan merupakan kawasan konservasi laut yang telah ditetapkan oleh pemerintah sejak tahun 1973. Luas wilayah perairannya mencapai 998 hektar dan saat ini tercatat mengalami kerusakan sebesar $60 \%$ yang dipengaruhi oleh faktor perubahan iklim, peningkatan suhu air laut, dan pemutihan karang (bleaching). Namun faktor utama penyebab kerusakan terumbu karang adalah aktivitas manusia seperti penggunaan bom yang mengakibatkan kerusakan parah di beberapa titik. (Pertamina.com, 2018)

Rehabilitasi terumbu karang pulau Ombo, dimulai sejak Juli hingga Desember 2017. di bagi dalam beberapa tahapan antara lain Tahapan rehabilitasi terumbu karang yang dilakukan meliputi identifikasi potensi terumbu karang; transplantasi karang yang terbagi menjadi dua kegiatan yaitu pembuatan substrat dan rak serta penanaman karang di laut,; dan monitoring \& evaluasi untuk memastikan pertumbuhan karang dan pembersihan dari bendabenda yang mengganggu pertumbuhan karang. Adapun jenis karang yang dikembangkan diantaranya karang cabang/acropora, montipora, karang tanduk/staghorn coral.

Unit Manager Communication \& Relations MOR VIII, Eko Kristiawan dalam sambutannya menyampaikan apresiasi dan dukungan terhadap pelaksanaan program konservasi terumbu karang sebagai bagian dari Corporate Social Responsibility (CSR) PT Pertamina (Persero). "Pertamina senantiasa mendukung upaya pelestarian biota laut di wilayah Pulau Pombo khususnya terumbu karang karena memiliki peran penting dalam ekosistem laut sebagai media perkembangan biota dan menjadi habitat ikan-ikan. Dalam jangka panjang, terpeliharanya terumbu karang di wilayah Pulau Pumbo juga dapat berpotensi menjadi objek wisata bawah air yang menjadi destinasi para wisatawan. Dengan demikian program CSR Pertamina dan kerjasama dengan BKSDA dapat memberi manfaat yang berkelanjutan bagi alam sekaligus bagi perkembangan ekonomi melalui pariwisata," (Pertamina.com, 2018)
Kepala BKSDA Provinsi Maluku, Mukhtar Amin Ahmadi menyatakan, lokasi Pulau Pombo ini aksesnya sangat terbuka dengan masyarakat dan banyak ditemukan pencari ikan di lokasi ini, sehingga tersisa dari luas perairan ini hanya 30 persen yang masih bagus. "Kami terus upayakan agar potensi biota laut yang tersisa bisa terus dilestarikan. Salah satu upayanya ada tim pengawas yang melibatkan masyarakat untuk mengawasi perairan ini agar tidak di bom lagi," (Ekspress, 2018)

Dengan Program konservasi terumbu karang di Pulau Pombo sebagai salah satu program bina lingkungan Corporate social responsibility Pertamina yang bekerja sama dengan Balai Konservasi Sumber Daya Alam Maluku merupakan wujud sinergi dan komitmen Pertamina terhadap upaya konservasi sumber daya alam di wilayah

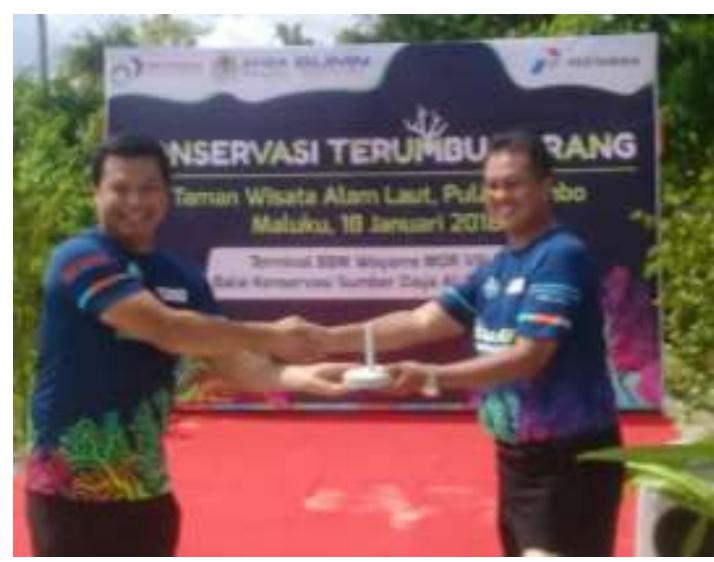

Indonesia Timur.

Sumber http://ambonekspres.fajar.co.id Gambar 3

Peresmian Konservasi terumbu karang di Pulau Pombon, Maluku

\section{KESIMPULAN}

Sebagai Negara maritime, ekosistem pesisir dan laut merupakan habitat yang penting bagi keanekaragaman hayati dan produktivitas perikanan di Indonesia, dengan banyaknya permasalahan yang di bidang pembinaan potensi maritim, diperlukan sinergi yang baik dari berbagai pihak baik pemerintah setempat, perusahaan, komunitas dan masyarakat yang terkait untuk dapat mengelola secara maksimal ekosistem laut Indonesia.

Pertamina dalam rangka mendukung program pemerintah melaksanakan berbagai program yang merupakan Implementasi Bina Lingkungan Corporate Sosial Responsobility untuk memberikan manfaat kepada masyarakat melalui pelestarian ekosistem laut di Indonesia. 
Implementasi corporate social responsibility Pertamina yang telah dilaksanakan dalam program bina lingkungan untuk pelestarian laut antara lain memberikan dukungan terhadap Wasi, memberikan bantuan alat peraga pendidikan lingkungan hidup. Rehabilitasi Terumbu Karang.

Dalam program Corporate Sosial responsibility Pertamina sudah menggunakan Prinsip Triple Botton Line atau 3p (profit, People, Planet) dalam mewujudkan komitmen perusahaan untuk senantiasa memprioritaskan keseimbangan dan kelestarian alam, lingkungan dan masyarakat. Dengan menyejahterakan manusia, alam, dan lingkungan, maka Pertamina akan mampu mencapai pertumbuhan bisnis yang berkelanjutan.

\section{REFERENSI}

Alamsyah, I. E. (2019). Aakademisi pencemaran laut tak hanya sampah plastik. Retrieved June 24, 2019, from https://www.republika.co.id/berita/nasional/u mum/19/06/24/ptm4dg349-akademisipencemaran-laut-tak-hanya-sampahplastik\%0AAkademisi: Pencemaran Laut tak Hanya Sampah Plastik

BBC.com. (2019). Paus di Wakatobi telan "115 gelas plastik" dan sandal jepit. Retrieved from https://www.bbc.com/indonesia/indonesia46284830

Djaelani, A. R. (2013). Teknik Penggumpulan Data Dalam Penelitian Kualitatatif, $X X$.

Donald, B. (2019). pertamina-lengkapi-sekolahmangrove-dengan-alat-peraga. Retrieved from https://www.cnbcindonesia.com/news/201907 18125609-4-85843/pertamina-lengkapisekolah-mangrove-dengan-alat-peraga

Ekspress, A. (2018). Pertamina dorong rehabilitasi terumbu karang. Retrieved from http://ambonekspres.fajar.co.id/2018/01/19/per tamina-dorong-rehabilitasi-terumbu-karang/

Emir, R. N. M. E. A. W. (2011). Panduan lengkap perencanaan CSR (1st ed.). jakarta: Penebar Swadaya.

Gunawan, Y. (2016). Gunawan, yordan, 2016, Pertanggungjawaban Indonesia Terhadap asap Lintas Batas negara Pasca Ratifikasi Asean Agreement on Transboundary Haze Pollution Universitas Muhammadiyah Yogyakarta. Pertanggungjawaban Indonesia Terhadap
Asap Lintas Batas Negara Pasca Ratifikasi Asean Agreement on Transboundary Haze Pollution.

Ilmugeografi.com. (2015a). ekosistem air laut. Retrieved from https://ilmugeografi.com/ilmubumi/laut/ekosistem-air-laut

Ilmugeografi.com. (2015b). pelestarian keanekaragaman hayati. Retrieved from https://ilmugeografi.com/biogeografi/pelestari an-keanekaragaman-hayati

Kriyantono, R. (2006). Kriyantono, Rachmat, 2006, Teknik Riset Komunikasi PT. Raja Grafindo Persada Jakarta. jakarta.

M, A. (2019a). Ancaman sampah plastik-untuk ekosistem laut harus-segera dihentikan bagaimana caranya. Retrieved from https://www.mongabay.co.id/2018/07/26/anca man-sampah-plastik-untuk-ekosistem-lautharus-segera-dihentikan-bagaimana-caranya/

M, A. (2019b). Seperti apa ancaman kerusakan ekosistem laut besar di Indonesia. Retrieved from

https://www.mongabay.co.id/2019/04/12/seper ti-apa-ancaman-kerusakan-ekosistem-lautbesar-di-indonesia/

maxmanroe.com. (2019). arti-implementasi.html. Retrieved from https://www.maxmanroe.com/vid/manajemen/ arti-implementasi.html

Moleong, Lexy, J. (2002). Moleong, Lexy, J, c Metode Penelitian Kualitatif, PT Remaja Rosda Karya, Bandung. Bandung: Remaja Rosda Karya,.

Nasrulhak, A. (2019). https://news.detik.com/pertamina-dukungwanita-selam-indonesia-pecahkan-rekordunia-selam? Retrieved from https://news.detik.com/berita/d4637173/pertamina-dukung-wanita-selamindonesia-pecahkan-rekor-duniaselam?_ga=2.54826159.58119670.156439163 6-1174865820.1549857409

Ningrum, A. O. C. (2015). Ningrum, Aminah Oktavia Cahaya, 2015) Analisis Pengamen Jalanan Di Kota Surakarta (Studi kasus Pengamen Jalanan di Kota surakarta). Skripsi thesis, Universitas Muhammadiyah Surakarta. Analisis Pengamen Jalanan Di Kota Surakarta (Studi Kasus Pengamen Jalanan Di Kota 
Surakarta).

Pawito. (2008). Pawito, 2008, Penelitian Komunikasi Kualitatif, LKIS, pelangi, Aksara, Yogyakarta. Yogyakarta: LKIS, pelangi, Aksara,.

Pertamina.com. (2018). program csr pertamina dorong rehabilitasi terumbu karang di pulau pombo. Retrieved from https://www.pertamina.com/id/newsroom/news-release/program-csr-pertaminadorong-rehabilitasi-terumbu-karang-di-pulaupombo

pertamina. (2019). pertamina.com. Retrieved from https://www.pertamina.com/id/pkbl

Ruslan, R. (2011). Ruslan, Rosady, 2011, Metodologi Penelitian Public Relations dan Komunikasi cetakan ke 5 rajawali pers Jakarta (cetakan ke). jakarta: rajawali pers Jakarta.

Sastrapradja Setijati D. (2010). Memupuk Kehidupan Di Nusantara (I). Jakarta: Yayasan Pustaka Obor Indonesia.

Wibisono, Y. (2007). Wibisono, yusuf, 2007, Membedah Konsep \& Aplikasi CSR, Fasco Publishing, Gresik. Gresik: Fasco Publishing,.

\section{Riwayat Penulis}

Siti Qona'ah S.Sos. MM lahir di Bandung, 26 Maret 1973 adalah dosen di Universitas Bina Sarana Informatika fakultas ilmu komunikasi dan bahasa program studi hubungan masyarakat sejak bulan Mei 2007. Pendidikan S1 yang ditempuh di Fakultas komunikasi Jurusan Public Relations di Institut Ilmu Sosial dan Politik (IISIP) selesai pada tahun 1997. Saat ini beliau sudah menyelesaikan pendidikan Strata dua (S2) Magister Manajemen pada Universitas BSI Bandung pada tahun 2012. Sebelum aktif di dunia pendidikan beliau bekerja pada bidang Penelitian, Penyiaran dan Perbankan. 